\title{
Els bandos de Valènsia o la paraula de sen Vicent Ferrer (1855): el primer milacre de Vicent Boix
}

\section{Els bandos de Valènsia o la paraula de sen Vicent Ferrer (1855): the first milacre of Vicent Boix}

\author{
JUAN ViCENTE FUERTES ZAPATA \\ juanvifz@hotmail.com
}

Universitat de València

\begin{abstract}
Resum: Un dels primers autors de milacres amb nom i cognoms coneguts, va ser el cronista de València, Vicent Boix i Ricarte (1813-1880). Aquella activitat seua va ser esporàdica, però és molt possible que el seu inici es puga situar el 1855, data del quart centenar de la canonització del sant. En aquella celebració, a més, Boix va ser l'encarregat d'elaborar el llibre commemoratiu i, d'aquell any és la publicació de la seua obreta Els bandos de Valènsia o la paraula de sen Vicent Ferrer, que analitzem en aquest article.
\end{abstract}

Paraules clau: Vicent Boix, milacres, treatre valencià, segle XIX

Abstract: One of the first authors of milacres with name and surname known, was the historian of Valencia, Vicent Boix i Ricarte (1813-1880). That activity was sporadic, but it is very possible that its beginning can be placed on 1855, date of the fourth centenary of the canonization of St. Vicente Ferrer. In that celebration, in addition, Boix was the one in charge to elaborate the commemorative book and of that year it is the publication of Els bandos de Valènsia o la paraula de sen Vicent Ferrer, that analyzes in this article.

Keywords: Vicent Boix, milacres, valencian theatre, 19th. century

\footnotetext{
* El present treball forma part del Projecte "Biografías marginales: violencia, sexo, género e identidad. Edición y análisis de las fuentes documentales valencianas de la época foral”, finançat pel Ministerio de Ciencia, Innovación y Universidades del Gobierno de España (PGC2018-097011-B-I00).
}

DATA PRESENTACIÓ: 10/10/2020 ACCEPTACIÓ: 19/10/2020 • PUBLICACIÓ: 10/12/2020 


\section{Els milacres vicentins i l'obra de Vicent Boix.}

Amb l'etiqueta de milacres s'entén un cert tipus de representacions teatrals que es troben immerses en la festa dedicada a sant Vicente Ferrer, i que es caracteritzen per l'interés en la figura del sant, que és el personatge principal o qui, al final, resol la situació. Per una altra banda, la representació del tema religiós adopta també un cert aire d'exaltació ciutadana, local, perquè es tracta, en resum, de fomentar la devoció popular de l'urbs valentina, bressol de sant Vicent, al seu fill preclar. La ingenuïtat dels textos, dels plantejaments dramàtics i la seua interpretació, sempre a càrrec de xiquets, també són detalls a tindre en compte en la seua caracterització, i això ens porta a poder parlar d'un caràcter marcadament infantil en aquestes representacions, encara que hem d'indicar que els temes no són, en moltes ocasions, tan «infantils» com podríem creure, d'entrada. A més a més, això ens porta a pensar que es poden relacionar els milacres amb algunes activitats teatrals o parateatrals que s'han pres com a antecedents del teatre infantil a Europa, com ja indicava fa anys Cervera (1983).

Els milacres vicentins, malgrat la seua presència anual i continuada durant més de dos-cents anys als carrers valencians, sempre al voltant de la celebració de la festa del sant, no han rebut massa atencions des de l'àmbit acadèmic i només podem assenyalar com a estudis més complets i quasi únics els de Juan Cervera (1983) i Josep Lluís Sirera (1999) i el catàleg de Martínez Ortiz (1955). Darrerament, nosaltres també hem fet alguna aportació, arran dels treballs preparatoris d'aquesta tesi, on ens hem centrat en textos altres que els de Boix (Fuertes, 2014; Fuertes \& Vilaplana 2014). No obstant això, un recorregut per les biblioteques públiques i privades valencianes $i$ els indicis aportats pels investigadors citats permeten intuir un camp de gran riquesa per a l'historiador de la llengua, la literatura i la cultura dels valencians, perquè des de principis del XIX i fins als nostres dies les representacions d'aquestes obres s'han succeït quasi ininterrompudament.

En el sentit que apuntàvem ara mateix, caldria destacar que els milacres són un fet cultural viu, que no s’ha fossilitzat, sinó que ha anat evolucionant amb el pas del temps, i per això pot resultar una mena d`espill de la realitat sociolingüística dels valencians. I segurament, ens podem remuntar fins i tot a leedat moderna, una època en què, si bé en la literatura valenciana hi ha un marcat descens de producció (Escartí, 2012), els milacres no sols van tindre el seu origen, sinó que van anar prenent la forma que actualment tenen. Sembla, però, que dels segles XVII i XVIII no ens han arribat exemples de milacres, però sí informacions suficients com per deduir que, en els altars efímers que es posaven als carrers de València -en especial, en les festes centenàries dels anys 1655 i 1755, però també en altres moments-, formes embrionàries de milacres -representacions parateatrals amb autòmats i amb participació de xiquets- podem detectar-les a través de la documentació que ens ha pervingut. No fa massa, ho indicava així V. J. Escartí (2019: 64-69), en el seu llibre destinat a recordar les celebracions vicentines centenàries, en parlar de la de 1655.

Encara que, certament, serà durant el període de la renaixença quan aconseguiran un major auge i contribuiran a enaltir més la figura de sant Vicent, fins a convertir-lo en símbol nostàlgic d'un 
passat que es creu cada vegada millor i que passa a formar part d'una visió romàntica de l'edat mitjana. De fet, sant Vicent mateix serà un dels tres puntals -al costat de Jaume I i el poeta Ausiàs March- en què descansarà la imatge del passat valencià, com ha destacat recentment Roca (2013).

Però, tornem als textos teatrals vicentins i els seus orígens, que hem de buscar-los en altres manifestacions tingudes com a punt d'arrancada del teatre modern europeu, i el de l'infantil en particular. Així, el cant dels tropos, el cant de la Sibil la, el teatre hagiogràfic, la festa del bisbetó i les roques o entremesos que es representaven en diferents processons i actes litúrgics religiosos són manifestacions teatrals o parateatrals que es poden posar en contacte amb un més que probable origen remot de les representacions vicentines que centren el nostre interés (Cervera 1983: 16-30). Encara que no és del tot clar en quina mesura participen els uns i els altres en l'aparició i maduració dels milacres. I això, fins al punt que no resulta fàcil establir el moment exacte que van començar a representar-se: malgrat posseir referències anteriors que podrien situar aquestes manifestacions en el segle XVII -amb formes embrionàries (Cervera 1983: 62-66), com ja hem dit més amunt-, s'ha de marcar el segle XIX com a segle en el qual més milacres s'han produït i els textos dramàtics del qual han arribat a nosaltres en forma de fullets impresos i, alguns, manuscrits (Cervera 1983: 67-78; Martínez Ortiz 1955).

La producció anterior -si posseïa textos escrits i no era confiada a la memòria personal-, per desgràcia no ens ha arribat. Segurament, en principi va haver-hi una combinació de quadres plàstics i fins i tot la participació dels autòmats ja esmentats amb xiquets que representaven les suposades escenes de la vida de sant Vicent, com s'ha encarregat de demostrar Cervera (1983: 31-61). De fet, també podríem suposar que existia un marge ampli per a la improvisació oral dels diàlegs, sobretot quan l'argument del que es representava era conegut, també, pel públic. Entre altres coses, perquè els relats dels miracles de sant Vicent Ferrer -és a dir, el relat dels actes taumatúrgics que eren coneguts, bé pel procés de canonització, bé per la tradició oral que havia imaginat lliurement diferents seqüències miraculoses atribuïdes al sant-, ja constituïen un corpus definit en les tradicions orals que s'havien anat transmetent de generació en generació. Encara que també hauríem de destacar el fet que, sovint, el propi text del milacre té un origen més aviat erudit, en contacte amb les hagiografies més esteses del sant. Bastarà com a exemple comentar que, en alguns casos, quan s`ofereix un resum de l'«argument» en els preliminars, a vegades se sol remetre específicament al text on s'inspira l'autor, com succeeix en el Milacre que sen Visent Ferrer alcansà de Déu nostre Sinyor estant en el consell de Casp, any 1412, titulat «El diable en la venda», de Josep Garulo i del 1855, on se'ns informa que el text deriva d'una de les hagiografies que van córrer major fortuna i van conéixer més edicions: la de Francesc Vidal i Micó, que degué gaudir d'una gran popularitat (Vidal 1735). Una font que va ser usada des del principi, i que trobem, fins i tot, en el primer milacre imprés -i anònimque es coneix: La font de Llíria, del 1822 (Fuertes 2014). El mateix Vicent Boix no s'estarà d'utilitzar aquella font explícitament al seu La creu de la peña, del 1868 -com es veurà més avall. 
Així doncs els milacres, encara que s'enquadren perfectament entre les manifestacions festives del poble i dels estaments més senzills, també podrien tindre un clar origen més complex i, en certa manera, «popularista» - en l'accepció que li atribueix Ferrando (1987) a aquesta mena de literatura-, fins ara no remarcat, perquè el mateix origen erudit d'alguns arguments així ens ho fa pensar: textos manipulats des de les sagristies o els convents, o des d'un dels homes que passaven per ser dels més brillants de la València del XIX -el nostre Boix-, i que eren dirigits al poble per a mantenir o augmentar la devoció vicentina entre uns devots que, si bé ja sabien quins eren els miracles del seu sant local, s'alegraven en veure'ls representats cada any, ben sovint amb textos nous que, només en alguns casos, arribaven i tot a la impremta. El fet d'usar fonts erudites -encara que relativament popularitzades, com la citada Vida escrita per Vidal o unes altres-, ho corroboraria.

Ara bé, com ja hem dit, l'objectiu immediat dels milacres no és cap altre que escenificar, amb diàlegs i una mínima actuació -i, de vegades, amb elements de decorat que indica l'autor o que podem inferir del desenvolupament de la mateixa representació-, un episodi miraculós on va intervindre directament el sant. A més, sempre hi ha una trama més o menys còmica i més o menys secundària que s'intenta combinar amb aportacions costumistes i elements de crítica social molt matisada $i$ -almenys en el cas de Boix- adreçada a generar una major sensació de pau i harmonia entre les diferents classes socials i, també, d'exaltació dels sentiments patriòtics locals. No obstant això, en molts casos els temes tractats poden ser banals, sense perdre de vista que assumptes melodramàtics i fins truculents poden aparéixer amb bastant assiduïtat. A això cal afegir l'element folklòric, que té aportacions significatives, i l'humorístic. Tot açò, reflectit en un registre col loquial de la llengua parlada a la València del XIX, amb nombrosos castellanismes que segurament no podríem definir-los com a vius en la llengua del moment, sinó que derivarien de l'escena teatral valenciana majoritàriament en castellà- $\mathrm{i}$ que els mateixos autors dels milacres -que ens arriben sovint anònimsrecollirien en els seus textos amb ànim de burlar-se potser d'aquelles «modernitats». Vicent Boix, en aquest sentit, ens dona la clau per entendre-ho millor: mentre els seus discursos i poemes renaixencistes són farcits de cultismes, arcaismes i, fins i tot, formes orientals de la llengua, els milacres es troben profusament esguitats de castellanismes i col loquialismes de caire molt local i castís, com es pot veure en l'anotació a peu de pàgina que hem fet dels textos editats ací.

Des d'un altre punt de vista, hem de dir que l'escassetat i la imprecisió de dades anteriors al segle XIX obliga a ser cauts quant a la possible determinació del període d'aparició dels milacres, com ja s'ha dit, i tal com els coneixem ara: peces amb un o diferents actes, clarament teatrals. És més, tot el que es pot dir, amb anterioritat al segle XIX, cau de ple, ara com ara, en el terreny de la conjectura. I, malgrat les aportacions ja realitzades -Martínez Ortiz (1955), Cervera (1983), Sirera (1999), bàsicament- hem drafirmar que només quan es faça un inventari exhaustiu i convenient de totes les peces conservades, i la seua catalogació detallada, s'estarà en condicions d'oferir un panorama més extens sobre un producte cultural i literari que al llarg del segle XIX va donar símptomes fins a cert punt inusitats d'una gran vitalitat de la llengua a València. 
No obstant això, en fer un breu recorregut pels textos que ara es coneixen, si bé podem afirmar que des de principis del XIX són bastant freqüents les edicions d'aquests, observem que a partir de 1851 les publicacions augmenten d'una manera remarcable. Potser, per la proximitat del centenar del 1855. Ara bé, serà a partir de 1870 -i fins a 1920- quan els milacres apareixen amb una regularitat que pràcticament arriba a un nou text per any (Cervera 1983: 85). A tot això hauríem d'afegir que molts dels milacres estan basats en altres textos o versions anteriors i que alguns d'ells van ser editats en diferents ocasions, amb la qual cosa, en molts casos s'hauria de traçar un arbre genealògic pertinent, per a arribar a les redaccions més primigènies 0 , també, a les diferents versions que van córrer impreses o manuscrites per la València del moment i que, fins ara, no hem detectat o senzillament s'han perdut per sempre.

Pel que respecta a la difusió dels milacres, es pot veure clarament que la circumstància de la seua representació en les festes anuals vicentines limitava la seua «actualitat» i, d'altra banda, perpetuava usos i costums, en convertir-se en una cosa tradicional i, així, amb escasses possibilitats de canvi: el públic, en aquests casos, reclama veure una vegada i una altra el que ja era conegut, sent les innovacions freqüentment mal rebudes, de manera que es perpetuen alguns títols, algunes escenes ja solidificades entre el públic, que es repeteixen any rere any i de les quals, les de Boix, en formen part.

En qualsevol cas, per damunt dels seus orígens encara incerts i més enllà de les seues limitacions estructurals, argumentals o ambientals, els milacres són una manifestació cultural i parateatral -i teatral- de primera magnitud, la singularitat de la qual dins de l'àmbit lingüístic i literari en català els fa mereixedors d'un estudi detallat i de conjunt que només arribarà quan ens trobem en condicions de saber amb quants exemplars comptem, i quan siguem capaços de reunir les notícies referents a les seues representacions de carrer, els seus actors, els seus escenaris, etc. Un repte, encara, per als investigadors $\mathrm{i}$ erudits. Bastaran unes dades, per a adonar-nos de l'abast d'aquest gènere. Autors com Joaquim Badia i Adell, Joaquim Balader, Josep Bernat i Baldoví, Vicent Boix, Joan Arolas, Salvador Calvo, Josep Garulo, Lluís Navarro, Miquel Preciado, Germà Roig i Florèncio, Manuel Sànchez Navarrete i uns altres, compten entre els seus escrits amb milacres. D’alguns, com Josep Garulo i Villel ens han arribat referències de quatre textos editats a mitjan XIX, de Joaquim Badia -de finals del mateix segle i principi del següent- coneixem més d'una quinzena de textos, entre els editats i els que ens han arribat manuscrits (Ribelles 1978: 136-138). D'alguns arguments dels suposats miracles, coneixem més d'una versió: com ara, de La font de Llíria, del qual sabem que va ser versionat, a més, per diferents autors (Fuertes 2014).

No obstant això, la documentació que coneixem sobre els milacres ofereix, encara, algunes llacunes. Tot i que, com hem dit, podem situar-ne els orígens a la fi del segle XVIII o principis del segle XIX, l'aparició dels altars vicentins es remunta al segle XV i més exactament al 1461, data en què es va bastir el primer al carrer de la Mar, a València (Cervera 1983: 31-38). Ara bé, tenim dos tipus de fonts: la més tardana d'aquestes la constitueixen els textos dramàtics coneguts dels milacres, els 
exemplars dels quals més antics han de situar-se a principis del segle XIX i arriben fins als nostres dies, com ja hem indicat. L'altra font, la que aporta dades sobre representacions de carrer dels milacres abans del segle XIX, es basa en referències bibliogràfiques. La pràctica d'edificar altars en honor de sant Vicent Ferrer va anar estenent-se a la ciutat de València, segurament des del mateix moment de la canonització del sant dominic, el 1455. Ara bé, encara que els alçats en honor de sant Vicent han sigut els més cèlebres i importants, també s'han alçat altars en honor a la Mare de Déu i d'altres sants lligats especialment a València (Cervera 1983: 25). Però pel que afecta a la devoció vicentina, sabem que l'altar del carrer de la Mar és el més antic, i, a això hauria d'unir-se així la coneguda col lecció de bultos -figures- de la parròquia de Sant Esteve. No obstant això, el costum de muntar altars degué estendre's en gran manera, perquè consta que en 1748 i, per ordre de Ferran VI, es prohibia la formació d'altars exceptuant si era en honor a Sant Vicent i, concretament a la seua festa al carrer de la Mar (Cervera 1983: 78).

Sembla que, a més, en els altars solien aparéixer les lògiques representacions plàstiques -pintures o figures- d'altres miracles als quals s'al ludia en els poemes exposats en el mateix lloc o en els seus voltants -com podem veure en algun milacre escrit per Boix i, també, per altres autors. En canvi, les representacions dramàtiques es limitaven a representar un miracle, el milacre, sobre el cadafal de l'altar, i era, així, el tema central. A això hem d'unir, per a formar-nos una idea més exacta de l'entorn on es representa el milacre, l'exhibició de figures de drap i cartó o ninots, col locats sobre els cadafals i que acompanyava declamacions, col loquis o representacions dramàtiques. Això significa que s'ha d'admetre la presència de la paraula parlada al costat de les figues inanimades o encara que fora sota formes dramàtiques tan rudimentàries i populars que ni tan sols es destinaren al manuscrit i que, potser, serien recitades de memòria per alguns afeccionats. Els cadafals sobre els quals es representen els milacres reben el nom d'altars, nom que ha sigut confirmat pel seu ús constant. De fet, en l'actualitat aquests altars romanen desmuntats durant tot l'any, a excepció dels dies en què se celebren les festes vicentines. I segurament havia de ser així en els segles passats (Cervera 1983: $52-66)$.

A part d'aquests dos conceptes clau, com són altars i milacres, hem de recordar-ne també uns altres, com ara roca o entremés. Per roca entenem els carros triomfals que es treien -i encara es trauen- en la processó del Corpus de València -i en unes altres, com les de la proclamació del dogma de la Puríssima, el 1662 (Pedraza 1982). En aquestes roques sovint també es representaven escenes bíbliques o de la vida de sants, bé amb figures, bé amb personatges de carn i ossos. Les roques, els altars i els milacres marcaran, doncs, una línia cap al caràcter dramàtic de les representacions del gènere dels milacres, tal i com el coneixem ara, aproximant-se cada vegada més al teatre (Cervera 1983: 39). En aquest punt caldria afegir la tradició de peces curtes, com els entremesos, $i$ altres textos teatrals com els misteris - breus peces declamades per diversos xiquets en processons valencianes del Corpus-, que en certs casos fins i tot es conserven, com en el Misteri de sant Cristòfor i els pelegrins, el Misteri del rei Herodes i el Misteri d'Adam i Eva, els textos originals de la qual es remunten segurament ales primeres dècades del XVI, però que van ser impresos per primera vegada en el XVIII (Sirera 
2008), creant, tal vegada models d'impressió als milacres vicentins, que viurien un clar apogeu local al costat -O en paral lel- amb la presència del sainet com a fórmula de representació teatral d'èxit durant el XIX valencià i encara més tard (Sanchis 1980; Sansano 2014; Sirera 1994).

Només unes dècades més tard d'aquella activitat teatral inicial ara esmentada, trobarem la producció de milacres de Vicent Boix, la qual, fins al moment, la tenim conformada per onze peces i totes, ja, presenten les característiques que hem esmentat i que configuren aquell gènere: Els bandos de Valènsia o la paraula de sen Visent Ferrer (València: Joan (València: Joan Fenoll Bordonado, 1855), Els hòrfens de sen Visent (València: Josep Maria Ayoldi, 1860), Elpendó de València (València: Josep Mateu Garín, 1860), L'oràcul de Caspe (València: M. Piles, 1861), El metge prodigiós (València: Josep Mateu Garín 1861), Lo rey y l'apòstol (València: Josep Mateu Garín, 1862), Lo àngel y lo diable (València: J. Peydró, 1865), La pau de Molvedre (València: Salvador Martínez, 1865), La creu de la peña (València. Salvador Amargós, 1868), Lo toch de somatén (València: Josep Doménech, 1870) i Los de fora y los de dins (València: Llibreria de la Viuda i fill de Mariana, 1880). Tots ells els podem trobar, actualment, en diferents biblioteques valencianes, $\mathrm{i}$ alguns - pocs-, s'han reeditat en facsímil.

Una de les qüestions que més crida l'atenció de la producció de milacres de Boix és que, si bé la major part de l'obra del cronista va ser en castellà, en aquestes peces vicentines, destinades a ser representades per xiquets, l'autor va optar per la llengua del poble. Una llengua que, sense cap dubte, havia de ser de més fàcil memorització per als infants de València que s'encarregaven de representar les obretes dramàtiques en els carrers de la ciutat, tal com era i és costum, i que Boix es va estimar sempre i va ajudar a recuperar, dotant-la de prestigi (Martí-Badia 2014) com va fer, també, amb tot allò que provenia del passat dels valencians, a recordar el qual va col laborar amb la seua producció històrica $\mathrm{i}$ literària.

\section{Els bandos de València (1855): un context per al primer milacre escrit per Vicent Boix.}

Les festes vicentines del 1855 recordaven els quatre-cents anys que feia que Vicent Ferrer havia estat elevat als altars. Vicent Boix, cronista de la ciutat, va ser l'encarregat de narrar-ho tot, en un seu volum que porta per títol Fiestas que en el siglo IV de la canonización de san Vicente Ferrer se celebraron en Valencia i que va ser publicat per la Societat Econòmica d'Amics del País. El text, ben profús en detalls, porta, a més, quatre làmines amb roques que representen diferents moments de la vida del sant, i han estat reproduïdes recentment en el volum d'Escartí, el qual comenta in extenso el text de Boix, i al qual seguim (Escartí 2019: 111-122).

Així, convé assenyalar que el volum de Boix comença amb una justificació i unes reflexions que ens mostren en quines circumstàncies es va portar a cap aquella celebració, i on encara es noten els efectes de les darreres calamitats. Boix ho assenyala: «Valencia, cuya importante figura se destaca también en el gran cuadro histórico de España durante el tiempo que contamos del siglo XIX, ha pasado por las mismas vicisitudes que han agitado a los demás pueblos europeos y ha derramado a 
torrentes su sangre, sus lágrimas y sus tesoros», però, a la fi, no deixa de valorar el gran esforç fet per recordar a sant Vicent: «tranquila, reposada, risueña y casi feliz, Valencia ha obsequiado a su patrono, sin volver la vista atrás y sin levantar el velo del porvenir». Com ha assenyalat Escartí en comentar aquell pròleg:

Un to d'amargor i un to, també, de complaença en els avanços del seu segle, esguiten
aquest fragment de l'obra de Boix, cronista, que es justifica davant el passat i davant
el futur. I, encara, per justificar que València ha celebrat unes festes que ell s'encarregarà
de narrar fastuosament, justament immersa en tot aquell món a què es refereix i,
encara, després de dues epidèmies de còlera, el 1834 i el 1854 (Escartí 2019: 113).

El llibre vicentí de Boix comença amb un capítol dedicat a recordar la figura de sant Vicent com a religiós i home polític, mentre que el següent ja ens parla de la seua canonització, el 1455. El capítol tercer se centra en la contemporaneïtat de Boix i comença recordant els cronistes anteriors de les festes centenàries vicentines, i, a més, s'adreça a qui les narrarà, en el segle XX. El quart capítol tracta de mostrar com es varen organitzar les festes, i també es dediquen a això els capítols següents, mentre que després ja passa a narrar les festes amb molt detalls que ara no ens interessen. El capítol octau del llibre de Boix conté el relat del començament de les festes, i és descrit molt detalladament el carrer de la Mar, on es troba la casa on va nàixer sant Vicent.

Sí que ens interessa ara veure com, en arribar al lloc denominat el Tros Alt, Boix no deixa de referirse a l'activitat teatral que allà es desenvolupa, i més concretament, ens aporta una dada clau per al nostre propòsit. Així, diu:

se levantaba el altar de San Vicente, destinado, desde inmemorial, para la celebración de los
milacres (milagros), con un vistoso toldo que se prolongaba por toda la calle de la Bolsería,
a espensas de los mismos vecinos. Había ricas colgaduras y buenas pinturas y retratos,
abundancia de iluminación, y se representó, en idioma valenciano, como todos los milacres,
escrito espresamente, con el título de Els bandos de Valènsia o la paraula de sen Visent Ferrer, por
el cronista que esto vió y escribió.

L'obreta de Vicent Boix, que forma part de la seua producció en aquest gènere, juntament amb altres milacres que ell mateix va redactar per mantenir viva aquella tradició de la festa vicentina, és la que ara centra aquest treball $i$, amb les paraules del mateix autor, tenim constatada la seua representació efectiva i els detalls dels embelliments del carrer o la il luminació.

Boix continua el seu volum, després, amb la descripció de carrers, places, façanes, esglésies, capelles, etc., les roques i els carros triomfals que desfilaren en els actes vicentins (capítol 9), la cavalcada (capítol 10), les festes del dia de sant Pere (capítol 11), les funcions religioses (capítol 12), les «novetats» que es van incloure en aquell centenari festiu, respecte dels anteriors -quasi totes, de caire social- (capítol 13), la descripció de la processó general, on no sols s'expliquen les roques i els carros que hi participen, sinó les danses que les acompanyen, els vestits, la música, les imatges, 
etc. (capítol 14), i els actes de caritat i beneficència generats per la celebració, que són narrats en els capítols 15 i 16. Un balanç econòmic i una Corona poética a san Vicente on es troben bona part dels qui després seran figures destacades de la renaixença a València, tanquen el volum.

Però, tornem al seu text Els bandos de Valènsia o la paraula de sant Vicent, que sabem que va ser escrita $\mathrm{i}$ representada en aquell ambient festiu $\mathrm{i}$ amb un rerefons d'una certa crisi social i econòmica anterior. $\mathrm{Al}$ milacre que comentem trobem sant Vicent Ferrer, Gilabert de Centelles, Jaume Soler, Guillem Saplana, Lluc Esteve, Pere Codinats, el Lleig, una veu i homes del poble, a més de soldats de la companyia del Centenar de la Ploma, són els personatges que intervenen en aquesta obra teatral de Boix. Ara bé, els més importants i que tenen una major presència en el desenvolupament de la trama són Gilabert de Centelles i Jaume Soler, que encarnen els dirigents dels dos coneguts bàndols que en època del dominic sant Vicent Ferrer varen disputar-se el poder a la ciutat de València. Aquests dos personatges en concret els tenim documentats -almenys, amb aquests mateixos noms- al Llibre de memòries de la ciutat de València i tot just en una anotació on apareixen com a caps dels bàndols, i que Boix podia haver conegut perfectament, a través d'alguna de les nombroses còpies d'aquell volum memorialístic. Perquè, en efecte, amb data de 1395, el citat manuscrit recull notícies de bandositats entre els Soler i els Dies -facció a què pertany Gilabert de Centelles (Escartí \& Ribera 2019: 184-185). En realitat, Gilabert de Centelles acabà assassinant Jaume Soler. Gilabert de Centelles, conseller de Martí I, participà en la defensa de Catalunya contra les companyies dels Armanyac. Va ser fet presoner i la ciutat de València pagà el seu rescat. Capitanejà la facció dels Centelles, en oposició als Soler (Narbona Vizcaíno 2015; Vicent Baydal 2013).

Altres personatges amb un paper molt més secundari són Guillem Saplana, Lluc Esteve i Pere Codinats. El paper del graciós, que sol aparéixer a les altres obres teatrals de Boix, i que sempre basa el seu humor en aspectes molt bàsics -el menjar, el beure, el dormir, el no treballar... - és el Llec, que es troba més present, sobretot, a la part dinal del milacre. Amb tot -i com també podem trobar en altres dels milacres de Boix-, serà el Llec qui, després de tractar de posar pau, però, sobrepassat per la situació, apel larà a la presència del sant, el qual serà qui realment resoldrà el conflicte generat en l'escenari i que, en definitiva, significava un enfrontament global a nivell de la ciutat de València. Superat el problema, i després de la intervenció pacificadora del sant, el Llec se'ns mostra un personatge que intenta actuar de forma graciosa, ens diu que ell també ha intervingut en el conflicte i que gràcies al que ell ha predicat també s'ha aconseguit la pau a València. Cal també remarcar un tret característic en tots els milacres del sant i, concretament, en la figura del graciós. Aquest personatge, com en molts altres dels milacres que crearà després Boix, se'ns mostra en algunes ocasions més preocupat pel menjar que pel drama que s'està representant sobre l'escenari. En aquest cas, l'autor remarca com era d'important menjar en el temps de sant Vicent -però, potser, en una clara al lusió a l'època de misèria que li va tocar viure a ell mateix, en especial, entre els classes més desfavorides- i que aquesta era la seua preocupació bàsica. 
El conflicte representat pel cronista de València se situa el 1395 -el mateix any en què hi ha l'anotació del Llibre de memòries ja esmentat-, però, com que la mort del rei en Joan I va ser poc després -l'any 1396-, potser hem de creure que hi hagué una errada en la datació de Boix. Això, però, no obsta per entendre que el cronista va voler representat els diferents bàndols que arran de la mort del rei s'haurien creat suposadament a València, amb dos parcialitats: una a favor de mossén Jaume Soler i l'altra a favor de Gilabert de Centelles. Aquesta rivalitat va causar grans avalots a la capital, perquè sovint hi havia disputes, ferides, morts $\mathrm{i}$ assassinats. Cada nit hi havia assalts $\mathrm{i}$ es raptava gent, sense respecte a les persones majors ni als infants. La presència del rei Martí i la intervenció de sant Vicent Ferrer va calmar aquestes discòrdies que van deixar records molt tristos a la ciutat de València, segons ho planteja Boix.

El milacre consta d'un diàleg que s'estableix entre dos dels personatges, al principi, i dues escenes posteriors. Així, la peça comença amb un parlament entre Lluc i Pere. Ambdós comenten que estan cansats de suportar de la situació que està vivint-se a València, i, amés, deixen clar que no tenen res per a menjar i que cada dia es troben diferents persones mortes. Després de continuar parlant sobre el conflicte, es queixen per l'absència del sant i comencen a lloar la seua imatge i els seus actes. A l'escena primera apareixen Lluc i després el Llec, que pràcticament són el fil conductor de l'escena: el seu diàleg és molt llarg i parlen de la situació en què es troba la ciutat, tot aprofitant per fer-nosen una panoràmica. El Llec intenta convéncer Lluc que la solució no és la guerra i que el que cal fer és aconseguir diners per tal de menjar, fent veure el seu caràcter pràctic, allunyat dels ideals que se suposa que mouen als nobles per mantenir els seus enfrontaments. De sobte apareixen soldats que volen matar el Llec i, després, quan apareixen dos personatges més, Saplana i Guillem, el Llec els confessa que pertany al bàndol oposat. Això fa que Lluc se senta traït i vulga matar el Llec.

A l'escena segona ja apareixen Gilabert de Centelles i Jaume Soler i comencen a parlar sobre qui té el poder sobre València: Centelles apareix amb un penó a la mà que, segons ell, significa el poder de la ciutat. Quan sembla que va a començar la batalla en els dos bàndols, apareix de nou la figura del Llec. Aquest intenta posar pau i fer-los reflexionar: pretén que vegen que la guerra no és la solució i que les conseqüències que pot causa una guerra poden ser devastadores per a la ciutat. Ara bé, tot i fer diferents explicacions, no té cap poder de convicció, i tant és així que apel la a la vinguda del sant per poder convéncer els dos bàndols i que deixen l'enfrontament. Quan ja quasi s'ha perdut qualsevol esperança, apareix la figura del sant que, tot i que li costa, acaba convencent-los per tal que deixen les armes $i$ aturen la més que probable futura guerra. El sant, amb la seua capacitat de persuadir, aconsegueix que els dos bàndols deixen les armes i vagen a l'església a signar la pau i a anunciar a tot el regne que tant el bàndol de Gilabert de Centelles com el de Jaume Soler tornen a ser germans. La fi, per tant, és d'un èxit aclaparador de cara a la valoració del sant.

En aquest milacre -com també es podrà veure en altres peces de Boix, posteriors- la figura de sant Vicent se'ns mostra com un personatge pacificador, que intervé en el conflicte i que aconsegueix resoldre'l. Ara bé, en aquesta ocasió, la presència del sant és mostrada a través d'una intervenció 
més treballada, com si de fet Boix volguera demostrar que aconseguir aquella pau per al conflicte dels bàndols no fora fàcil, cosa que ell sabia perfectament. Tant és així que, fins i tot, un dels cap dels dos bàndols no acceptarà les propostes del sant, i només amb una nova intervenció que aquest fa, i després d'un llarg parlament on el convenç, acaba per resoldre's la situació.

La construcció del milacre, doncs, és bastant senzilla: hi ha un plantejament del conflicte als carrers de València, amb el rerefons de la crisi dinàstica. inspirat en una realitat històrica, i l'aparició de sant Vicent com a personatge que, amb la seua intervenció, posa pau i aconsegueix el bé per a la ciutat. Pràcticament, un plantejament que es repetirà al llarg de la resta dels milacres que coneixem de Vicent Boix.

\title{
3. Edició
}

\author{
ELS BANDOS DE VALËNCIA \\ O LA PARAULA \\ DE SEN VISENT FERRER.
}

AUTO SACRAMENTAL

QUE SE REPRESENTÀ EN EL ALTAR DEDICAT AL SANT,

PER LA CORPORASIÓ DEL TROS ALT, EN ELS FESTES DEL CUART SIGLE ${ }^{1}$

DE SA CANONISASIÓ,

AÑ 1855.

ESCRIT PER

DON VISENT BOIX, CRONISTE DE LA SIUTAT

\author{
VALÈNSIA, 1855 \\ IMPRENTA DE CHUAN FENOLL BORDONADO 2 \\ CARRER DE LA CONQUISTA, NÚM. 24
}

\footnotetext{
1 El 1855 es van celebrar festes a València, amb motiu del centenar quart de la canonització de sant Vicent Ferrer. El mateix Boix va elaborar un volum amb el relat ben detallat d'aquelles festes. Porta per títol: Fiestas que en el siglo IV de la canonización de san Vicente Ferrer se celebraron en Valencia. I allí, Boix, esmenta la representació d’aquesta peça teatral. Sobre aquelles festes i la participación de Boix, vegeu Escartí (2019: 111-123).

2 Joan Fenoll Bordonado aparéix documentat a l'obra de Serrano Morales (1898: 183) on se'l documenta entre 1850 i 1856 a València, imprimint «obras de poca importancia impresas en su casa».
}

SCRIPTA, Revista internacional de literatura i cultura medieval i moderna, núm. 16 / desembre 2020 /pp. 223-249 


\section{ARGUMENT}

En 1395, y poc después de la mort del rey don Jaume I, se dividí Valènsia en dos bandos o parsialitats que sostenia mosén Chilabert de Centelles contra mosén Chaume Soler, causant grans mals a la capital. Diàriament habia riñes, ferides, morts y asesinatos violents; per la nit se asaltaben les cases dels siudadans més pasífichs y se'n portaben als contraris sens respecte als ansians y als infants. La presènsia del rey don Martí, y la intervensió de sent Visent Ferrer, calmà estes discòrdies, que deixaren records molt trists en València, baix el nom dels Centelles y Solers, de què hi à moltes notísies en l'archiu de la siutat. ${ }^{3}$

\section{SEN VISENT FERRER.}

\section{PERSONES}

\section{GILABERT DE CENTELLES.}

CHAUME SOLER.

GUILLEM SAPLANA.

LLUCH ESTEVE.

PERE CODINATS.

EL LLECH.

UNA VEU (dins).

HÒMENS DEL POBLE: soldats del Sentenar de la Ploma. ${ }^{4}$

El teatre representa una plasa y dos carrers laterals, u enfront de l'atre.

\section{Lluch, de sentinela; Pere.}

Lluch: Ya la nit en gran quietut, per primer volta ham ${ }^{5}$ pasat.

Pere: Un añ aixina! ${ }^{6}$ Asò és trist, y així no podem estar.

Lluch: Cada dia, tres, sinch, deu, y, a voltes més. Durant l'añ veem morir als més valents, y enmig d'asò està la fam.

$\mathrm{Mos}^{7}$ falten els bastiments, ningú ve a vendre al mercat;

3 Hem comentat al text introductori les possibles fonts d'inspiració de l'autor.

4 Sobre la institució del Centenar de la Ploma, vegeu Narbona Vizcaíno (2015b).

5 Ham, forma col loquial per hem. Documentada des del segle XVIII, en obres com la Rondalla de rondalles, de Lluís Galiana, o el Resumen y relació de la vida y prodigis de Pere Esteve, de Leopold Ignasi Planells. Vegeu CIVA, s. v. ham.

6 Variant formal d'aixi. (DCVB)

7 Forma dialectal usada en gran part de les terres valencianes, en compte d'ens (DCVB) 
el vi s'ha puchat als núbols, està més car que el pa; el oli el tastem a penes, però, en cambi, sobra sanc. Et ferixen? A ta casa; el dimoni et curarà. Et quedes $\operatorname{sinse}^{8}$ una cama? Te desconserten el bras? O te obrin com un meló de una cuchillada ${ }^{9}$ al cap? Pues ves a morir, si pots, y et deixen algun forat. Y después? Si tens faena, tindràs també què menchar. Però, si para el ofisi, si tos fills no tenen pa, busca pedres del carrer, perquè ningú et donarà una set de aigua ${ }^{10} .$. . Asò és cert. $\mathrm{Y}$ tot asò és renegar.

Pere: Y per què? Y esta és més negra. Per què de tot asò? Vecham! Perquè don Chaume Soler, home molt acaudalat ${ }^{11}$ y de una ambisió estremada, vol a plaer manejar, sinse reparar en michos, el càrrechs de la siutat, disputant esta influènsia en el consell y churats, a Chilabert de Centelles qu és noble molt estirat, y que, engreït per demés, en els seus timbres y sanc, vol, a soles, en Valènsia, com rey absolut, manar. $\mathrm{Y}$ així, han format dos partits, que $n$ elecsions de churats, en les corts y consells,

8 Variant formal de sense. $(D C V B)$

9 Castellanisme no documentat al DCVB. El CIVA, de l'AVL, el documenta precisament en aquesta obra de Boix.

10 Aquesta expressió, que significa 'no donar res', ve documentada precisament a partir d'aquesta obra de Boix al Diccionari de fraseologia de Martí Mestre (2017: 1441), que segueix l'edició del 1878 que no hem tingut en compte, i de la qual només coneixem un exemplar conservat a la Biblioteca Pública de l'Estat de Castelló (CS-PP, Folletos, 104/49).

11 Mot documentat al CIVA, a partir d'aquest milacre de Boix. (CIVA, s.v.) 
Juan Vicente Fuertes Zapata. Els bandos de Valènsia o la paraula de sen Vicent Ferrer (1855): el primer milacre de Vicent Boix

se fiquem a disputar.

Primer en rahons, después

-el amor propi picat-, se insultàrem $\mathrm{y}$, per fi, vullgues que no, ham apelat a les armes, per a obtindre la victòria cada cual.

Lluch: Però, asò no tindrà un terme?

Pere: Però, ¿qui l'ha de posar, si en Valènsia no hi à un home que d'asò siga capàs?

Lluch: Yo em vaig cansant, Pere, amich. Perquè molts dies fa, ya, que sinch chiquets y la dona em demanen pa y més pa, y yo em rasque les bolchaques, y sempre buides estan.

Pere: Però, serem els primers que así demanem la pau?

Lluch: Ca! Tampoc! Ells han de ser. Sempre els habem derrotat, y, si no fóra que tenen, per a mal, tan bons caballs, no en quedaria ni hu, per a contar este cas.

Pere: Però, tenen el pendó... y asò, amich Lluch, és un mal, perquè se llig en els fueros, ${ }^{12}$ que, el que, venut o cobart, no seguixca la Señera, cuan ix la Señera al camp, siga jusgat com traïdor, y, com traïdor, castigat.

Lluch: Però, com se han fet en ell? Sols per mig de una maldat.

Asaltaren, per la nit, sens poder-lo remediar -y per ser, algú, traïdor-, la casa de la siutat

12 Castellanisme per furs.

SCRIPTA, Revista internacional de literatura i cultura medieval i moderna, núm. 16 / desembre 2020 /pp. 223-249 ISSN: 2340-4841 $\cdot$ doi:10.7203/SCRIPTA.16.19227 
Juan Vicente Fuertes Zapata. Els bandos de Valènsia o la paraula de sen Vicent Ferrer (1855): el primer milacre de Vicent Boix

y el pendó, luego, robaren...

Si asò és chust, Déu ho sabrà.

Pere: $Y$ hui tindrem tremolina? ${ }^{13}$

Y tots els carrers estan,

per lo que puga asò ser,

com atres voltes, guardats?

La precausió nunca sobra.

Lluch: Axí que se ha fet de dia,

han anat a soterrar

als nou hòmens que perdérem

aïr, en la catedral.

Però, digues: ¿tens un tros,

un poquet almeñs, de pa,

encara que siga dur

com el peu ${ }^{14}$ de un campanar?

Pere: Ni en tinch, ni nn tindré, amich Lluch.

Les cases del vehinat

he corregut una a una,

y en totes estan llampant.

Lluch: Home, veches per ahí.

Busca rincons y forats,

$y$, si en troves un moset,

recorda la mehua fam.

Pere: Quina llàstima, no estiga

Vicent Ferrer a la mà

per a què fera un milacre!

Lluch: El machor que fer podria, és, si pot, que yo no ho crech, posar-mos a tots en pau.

Pere: La hauran guañat els Centelles...

Lluch: Home, no...Visent és sant!

Pere: Pues, què vols? Serà molt sert

lo que crehus, però és estrañ

que no es vecha per así.

Lluch: Està fora.

13 Efecte de tremolar, pel fred o la por.

14 Es refereix al fonament $(D C V B)$ d'una obra, que normalment és de pedra.

SCRIPTA, Revista internacional de literatura i cultura medieval i moderna, núm. 16 / desembre 2020 /pp. 223-249

ISSN: 2340-4841 ·doi:10.7203/SCRIPTA.16.19227 
Juan Vicente Fuertes Zapata. Els bandos de Valènsia o la paraula de sen Vicent Ferrer (1855): el primer milacre de Vicent Boix

Pere:

Sempre anant

de reine en reine. No para.

És un apòstol.

Lluch: $\quad$ Y gran!

Pere: Si estiguera per así

asò se aguera acabat.

Però callem, allà ve

un home tot asorat. ${ }^{15}$ (Mirant cap a dins)

Lluch: No és home; és un frare, ves

y busca'm un mos de pa,

que vaig a detindre al frare.

Torna pronte, que la fam

me va deixant sens aliento

y casi no puch parlar.

\section{ESENA 1}

Lluch. Después, el Llech.

Lluch: Quins dies! Que confusió!

Pareix asò un campament,

ve la chent y va la chent

tots... criden. Qui té rahó?

$\mathrm{Si}$ asò dura un poquet més,

¡ni rates han de quedar,

cuant s'acabem de matar!

Y tot, per què? Per no res. (Ven al Llech)

Qui va ahí? Diga, qui és ell? (El Llech se fa el tonto)

No respon? Eh! Que li arrime... (Li amenasa en la alabarda)

Per mil sants! No se aproxime

o li destrose el servell.

Llech: Eh! Poc a poc... Que sóch yo...

Lluch: Y qui és ell?...

Llech: Un animal,

que se à soltad del ramal

y va buscant un rincó.

Lluch: A quin bando perteneix?

És del[s] Solers o Centelles?

Llech: Del bando de les paelles,

a hon se mencha carn y peix.

15 Castellanisme (DCVB). Amoinat.

SCRIPTA, Revista internacional de literatura i cultura medieval i moderna, núm. 16 / desembre 2020 /pp. 223-249

ISSN: 2340-4841 · doi:10.7203/SCRIPTA.16.19227 
Juan Vicente Fuertes Zapata. Els bandos de Valènsia o la paraula de sen Vicent Ferrer (1855): el primer milacre de Vicent Boix

Sóch un llech que va buscant un rincó per a estar quet, ${ }^{16}$ y, a Déu no siga retret, prench part a on estan menchant.

Lluch: Vosté és el llech que acompaña al pare Visent Ferrer...

Llech: Me coneix tot el carrer, a pesar de esta campaña.

Lluch: Y què busca per así?

Llech: Que sé yo! Dos hores fa que baig de así per allà, saltant com un taulaí. ${ }^{17}$ Ya $\mathrm{m}$ detenen, ya me agarren, ya me chiulen y, a pedrades, els chiquillos dos vegades m'an seguit y no se esmarren. ${ }^{18}$ «Tireu-li a eixe... Allà va! Pareix un colom perdut... Tireu-li eixe mich-armut ${ }^{19} . . . »$ Y, en seguida: plaf! Pedrà. Así em tiren una col, allà una granera bella, ${ }^{20}$ así un mànech de paella, y més allà algun perol.

Lluch: Y vosté no fea res?

Llech: Ells tiraben, yo també. Per cada pedra, yo, dos... però no hagut gat ni gos que no em chiulara de ple. Y diga'm, Lluch, a quin bando perteneix vosté?

16 Forma habitual a les terres valencianes per quiet. $(D C V B)$

17 Teuladí. La forma taulai seria un arcaisme.

18 Esmarrar: apartar-se del camí. Documentat sols en teres valencianes. (DCBV)

19 mig-armut: mig-almud: l'almud o armud és la quarta part de la barcella i equival a un poc més de quatre litres. $(D C V B)$

20 Llegiu: vella.

SCRIPTA, Revista internacional de literatura i cultura medieval i moderna, núm. 16 / desembre 2020 /pp. 223-249 ISSN: 2340-4841 · doi:10.7203/SCRIPTA.16.19227 
Juan Vicente Fuertes Zapata. Els bandos de Valènsia o la paraula de sen Vicent Ferrer (1855): el primer milacre de Vicent Boix

Lluch: Als Solers, perquè són més caballers que els de Centelles...

Llech: Andando.

Lluch: Y vosté?

Llech. Me esplicaré.

Què demanen tots así?

Per què han perdut el juí?

Eu vol saber? Ho diré.

Así tots volen manar

del poble, prenint la veu,

y tots en el nom de Déu

al poble el fan espichar. ${ }^{21}$

¿Per dos hòmens de ambisió

s'han de matar a trancaes?

Asò, amich Lluch, són bobaes:

menchar y veure és rahó.

¿No tenim en la siutat,

des de antich, molt bones lleis?

Per què volen tants de reis

si els sobra llibertat?

Amich Lluch, lo millor és

deixar-se de coscorrons, ${ }^{22}$

y guañar-se bons doblons

per menchar y veure més.

Lluch: Vacha en Déu, el borinot.

Tots els soldats: Fora eixe frare poltró! ${ }^{23}$

Lluch. Li aconselle que al convent

se en vacha apresa y corrent,

y pique bé de taló.

Tots els soldats: Mateu-lo a eixe llech... (Li amenasen)

Llech. Caferro! ${ }^{24}$ (Arromangan-se les mànegues)

Hu contra tants! No vol dir...

y avans que puga fuchir

hauran de medir el ferro. (Se retira cap a el atre costat y el deté un atre sentinela)

21 Espitjar: estrényer. $(D C V B)$

22 Valencianisme per colp al cap. $(D C V B)$

23 Segons el $D C V B$, significaria «peresós o malfaener», però la documentació aportada és només de a partir del Diccionari d'Aguiló..

24 Interjecció usada a l'Horta de València, segons el Diccionari d'Aguiló (DCVB)

SCRIPTA, Revista internacional de literatura i cultura medieval i moderna, núm. 16 / desembre 2020 /pp. 223-249

ISSN: 2340-4841 · doi:10.7203/SCRIPTA.16.19227 
Juan Vicente Fuertes Zapata. Els bandos de Valènsia o la paraula de sen Vicent Ferrer (1855): el primer milacre de Vicent Boix

Zaplana: Qui va allà?

Llech: $\quad$ No va, ni vé.

Semechant a un trompellot,

va anant este borinot,

perquè un ganibet no té.

Deixa'm passar...

Guillem: No se pasa.

Llech: És hora de refetor y està esperant el prior per a anar a serta casa.

(Mentires en ells y avant!)

Guillem: A quin partit perteneix?

Lluch: Y vosté?

Guillem: Que no ho coneix?

Lluch: Als Centelles?

Guillem. Sí.

Llech: $\quad$ Yo... en gran.

Lluch: (Des de l'altra part) Ah! Pícaro! M'ha engañat!

Però, no et riuràs de mi! (Li tira una flecha)

Els del meu partit: Así! (Ixen tots formats)

Lluch: (Cridant) Als meus! Así al meu costat (Disparen també. Confusiô)

Llech: (Procurant amagar-se) A ells! A ells! Que s'escapen!

Anem tots! Que sarrasina! $!^{25}$

Si em tornara tarañina!

Pues ells así no m’atrapen. (Se’n fuch)

Guillem: (Al llech) Así els braus! No y à perdó!

Nostra, amichs, és la victòria

$\mathrm{y}$, en prenda de esta memòria

defengam nostre pendó.

25 Baralla sorollosa. (DCVB)

SCRIPTA, Revista internacional de literatura i cultura medieval i moderna, núm. 16 / desembre 2020 /pp. 223 -249

ISSN: 2340-4841 · doi:10.7203/SCRIPTA.16.19227 
Juan Vicente Fuertes Zapata. Els bandos de Valènsia o la paraula de sen Vicent Ferrer (1855): el primer milacre de Vicent Boix

\section{ESENA II}

Ix Gilabert de Centelles en el pendó y Chaume Soler va a l'encontre de ells.

Centelles: (En lo pendó en la mà) Esta és la enseña sagrada que Valènsia ha conquistat en ses lleis y llibertat per don Chaume consignada. Cuansevol qu este pendó no seguixca, ab gran valor el declare, así, traïdor, y a mort el provoque yo. Soler! En lo nom del rey, te mane que, achenollat, respectes $m$ autoritat que representa a la lley.

Soler: ¿És lo poble valensià, achuntats en corts, un dia el que a manar-me t'envia que te bese así la mà? Als teus y al poble traïdor has volgut tiranisar: als que poden conquistar la llibertat en honor. Qui més sang ha derramat? No eres tu? No són els teus? Estos que así tu veus (Señalant als seus) Valènsia no ls ha estimat? Per insígnie traïsió, en tota lley reprobada, y en una nit desgrasiada nos robares el pendó.

Centelles: Yo, traïdor? Yo un caballer! ¡Per sent Chaume, que has mentit!

Soler: Dit està, lo que te he dit. No torna arrere un Soler.

Centelles: Pues a les armes, amichs! (Chirant-se als seus) Ahí teniu al malechor! ${ }^{26}$ Acabe nostre valor en eixos llops enemichs! (Preparen tots les armes)

Soler: Te esperem, Centelles fort, y avans que rendir-nos, hui, Valènsia tindrà son fi,

26 Castellanisme per malfactor. 
Juan Vicente Fuertes Zapata. Els bandos de Valènsia o la paraula de sen Vicent Ferrer (1855): el primer milacre de Vicent Boix

y en ella estarà la mort. (Toquen algunes campanes arebato. Se acometen els bandos. Soler procuparà arrebatar el pendó que Centelles defendrà en valor y forsa).

Llech: (Ix, arromangat els brasos y el hàbit, y una pedra en cada mà, y se posa enmich)

Alto, tots els guapetons!

Alto tots els que así estan!

Vach a parlar. Me ohiran?

Escolteu-me valentons.

Per plases y per carrers,

cap amunt y cap a vall,

per totes parts y à treball. (La chent de Soler murmura)

Callen eixos bachillers!

Per totes parts van, a trosos,

entre rosins, ${ }^{27}$ destrosats,

y entre la sang, soterrats,

les cames, els caps y els osos.

Siudadans y caballers

y dones -que és lo pichor-,

se rebenten, en furor... (La chent de Centelles mormura)

Callen eixos bachillers!

Y tot asò per a què?

Perquè tots volen manar..

Asò no és viure, és rabiar

y matar-se sinse fe.

Què faran, estaquirots, ${ }^{28}$

les viudes que deixareu?

Y els hòrfens que tindreu? (Murmullo de tots)

Calleu tots els borinots!

Tots: Fora el loco! Fora! Fora! (Se preparen altra volta per a pelear)

Llech: No m'escolteu, malaïs?

Esteu, de ràbia, podrits!

Pues mateu-se así, en bon hora! (Se fa arrere y comensa a cridar)

Ay, pare Visent Ferrer!

Vinga a posar-los en pau! (Se escolta una trompeta y queden parats els batalladors)

Tots: Arrere! Arrere!

Una veu: (Des de dins) Escoltau...

Llech: Obriu pronte! Feu carrer! $!^{29}$ (Ix sent Visent Ferrer, el Llech se posa en seguida al seu costat, els combatients fan rogle)

27 Rossí, tipus de cavall $(D C V B)$.

28 usat, ací, en sentit pejoratiu: Persona curta d'enteniment. (DCVB)

29 Frase feta per indicar obrir pas. (DIEC)

SCRIPTA, Revista internacional de literatura i cultura medieval i moderna, núm. 16 / desembre 2020 /pp. 223 -249

ISSN: 2340-4841 · doi:10.7203/SCRIPTA.16.19227 
Juan Vicente Fuertes Zapata. Els bandos de Valènsia o la paraula de sen Vicent Ferrer (1855): el primer milacre de Vicent Boix

Llech: Ay! Pare meu, què va a fer?

Cuant yo, que sóc elocuent,

no he pogut calmar la chent...

A trompis ${ }^{30}$ bé podrà ser.

Sen Visent: (Els mira a tots de espay, contempla aquell aparato en sentiment y diu después:)

Sempre en guerra, chermans meus?

Y sempre el mateix furor?

Per què tanta crueldad?

Per què tanta destrucció?

Llech: (A part) Malo! Malo! Fes-los mimos...

Si tenen cor de lleó!...

Sent Visent: Vos és grat, fills de Valènsia,

vore el aspecte de horror

que eixes discòrdies presenten,

davant del poble, que és bo?

No escolteu tantes angústies,

tans de lamentos y plors,

que vostres mullers y fills

derramen en la aflicsió?

Llech: (A part) Ay! Ay! Sols a trancades

es predica un bon sermó.

Sent Visent: ¿ ¿No compreneu, chermans meus,

que a vostra sombra és machor

la audàsia dels criminals,

que aprofiten la ocasió

per a fer els seus delits?

Ohuïu la veu del Siñor!

En tot poble dividit

està la ruïna $\mathrm{y}$ mort.

No volen la llibertad?

La dels fueros és millor,

Ay! del que mate a la pàtria

per sa culpa y ambisió!

És asò ser bons cristians?

Mana asò la relichó?

Llech: (A part) Nostre pare ho fa molt bé,

predica tan bé com yo.

Sen Visent: En cambi, quina alegria,

quin entusiasme y quin goig

tindrà el poble de Valènsia,

30 Paraula del castellà, col loquial, trompazo. (DRAE)

SCRIPTA, Revista internacional de literatura i cultura medieval i moderna, núm. 16 / desembre 2020 /pp. 223 -249

ISSN: 2340-4841 · doi:10.7203/SCRIPTA.16.19227 
Juan Vicente Fuertes Zapata. Els bandos de Valènsia o la paraula de sen Vicent Ferrer (1855): el primer milacre de Vicent Boix

si, deposats els rencors, se abraseu com a chermans, y com ho mana el Siñor! Donareu la pau al poble y no ho y haurà así un rincó a hon vosatros no os donen mil vítors ${ }^{31}$ y bendisions. Ploraran vostres mullers, de goig y consolasió, y vostres fills, agafats per plaer del vostre coll, en tendres veus premiaran tan santa resolusió.

Ànimo, fills, què ducteu? ${ }^{32}$ Fora eixes armes y al món doneu el eixemple gran de què sols en la ocasió de la pàtria als enemichs mostrareu eixe valor.

Pronte, les armes a terra! (Els guerreros baixen les armesy els caps)

Valensians, obriu el cor!

Pau y chustísia a Valènsia!

Fes lo demés, tu, Siñor! (Alsant els brasos y els ulls al sel y se queda així un momento)

Llech: (A part) Ji, ji, ji! Qui me diria

que tan blanet fora yo!

Però, què bé hem predicat!

És que así ham estudiat molt!

Però els galopos ${ }^{33}$ se callen...

No els ha fet mella ${ }^{34}$ el sermó...

Si els faltarà este argument! (Alsant el puñ)

Els caballers, què? S'han mort? (Dirichin-se als bandos)

Centelles: Yo no me humille el primer...

Sóch caballer de valor!

Llech: Caballer? Pues, no és cristià?

$\mathrm{O}$ viu sinse relichió?

Soler: Yo el primer no done un pas...

Mehua no fon la agresió.

31 Victor, aclamació; deu ser valencianisme, atés que el $D C V B$ només el documenta en Teodor Llorente.

32 Ducte és un dialectalisme occidental i valencià. $(D C V B)$

33 Deu ser variant de guilopo (persona curta d'enteniment o vivaç i maliciós, segons el DCVB).

34 Castellanisme ja present a València des del temps de Timoneda. (DCVB)

SCRIPTA, Revista internacional de literatura i cultura medieval i moderna, núm. 16 / desembre 2020 /pp. 223-249

ISSN: 2340-4841 · doi:10.7203/SCRIPTA.16.19227 
Juan Vicente Fuertes Zapata. Els bandos de Valènsia o la paraula de sen Vicent Ferrer (1855): el primer milacre de Vicent Boix

Llech: Tu també? Pare Visent...

És més dura que un cantó,

esta chent de barrabàs... (Repara en el sant, que està en èstasis)

Què veig? Ensomie yo?

Se ha dormit... Però, així, dret?

O és que 1 dechuni y sermó

le ha deixat desvalait?

Pare Visent... què fas yo? (Cridant)

Sen Visent: (Tornant en si) Tu ho vols Siñor... Siga així.

Llech: (A part) Parla a soles... bo, bo, bo...

Sen Visent: Escolteu-me... Tots voleu

en la millor intensió

acabar ya estes discòrdies,

però, el diable, siñors,

os ha tentat en lo orgull.

Mes, yo venseré el furor

del diable ya vensut...

de Valènsia en el gran nom,

en nom de les sehues lleis,

y en nom de Déu...

Llech: (A part) Asò és fort!

Sen Visent: Os declare, valensians, (se acosta a Centelles y li pren el pendô)

que el que no acate el pendó,

que alse así en nom de la lley,...

no sols no és cristià: és traïdor!

Tots: (Achenollant-se) Ah!...

Llech: Gràsies a Déu, que han fet

lo que és chut de borinots...

Sen Visent: Esta és la prenda, fills meus,

de la vostra pau y unió.

Ella vensé als enemichs,

ella serà la millor

prenda que sempre tindreu

de esta reconsiliasió.

Qui faltarà a esta promesa?

Tots: Ningú, ningú!

Sen Visent: Bé ho sé yo.

Baix esta insígnia de glòria,

ningú serà ya traïdor,

SCRIPTA, Revista internacional de literatura i cultura medieval i moderna, núm. 16 / desembre 2020 /pp. 223-249

ISSN: 2340-4841 · doi:10.7203/SCRIPTA.16.19227 
Juan Vicente Fuertes Zapata. Els bandos de Valènsia o la paraula de sen Vicent Ferrer (1855): el primer milacre de Vicent Boix

y en el nom de la siutat y en pro de la relichó, per ella estareu en pau, en ella sereu vensedors. Ho cumplireu, pues?

Tots: Sí...sí...

Sen Visent: Beneït siga el Siñor! Anem, pues, al temple sant a confirmar esta unió... $\mathrm{y}$ anunsiar a tot el reine que sou ya chermans de cor.

Tots: Viva sen Visent Ferrer! (Seguixen a sen Visent. El Llech se queda a soles)

Llech: (Alpúblich) Ya que s'acabat asò, y he treballat... però, cuant!, -encara em cau el suorels deixe anar a la iglésia. Yo me'n vach al refetor. 
Juan Vicente Fuertes Zapata. Els bandos de Valènsia o la paraula de sen Vicent Ferrer (1855): el primer milacre de Vicent Boix

\section{Bibliografia}

Cervera, Juan (1983) Los milacres vicentinos en las calles de Valencia, València, Del Cenia al Segura.

Escartí, Vicent Josep (2012) From Renaissance to Renaissance. (Re)creating Valencian Culture (15th. - 19th. c.), Santa Bárbara/Ciudad de México, Publications of eHumanista.

- (2019) Celebrar sant Vicent: festa i literatura. La ciutat de València i les festes dels centenars de la canontració de sant Vicent Ferrer, València, Ajuntament de València.

Escartí, Vicent J. \& Ribera, Josep (2019). El llibre de memòries de la ciutat de València, València, Ajuntament de València.

DCVB = Diccionari Català-Valencià-Balear [https://dcvb.iec.cat/].

DRAE = Diccionario de la Real Academia de la Lengua Española [https://www.rae.es/].

Ferrando, Antoni (1987) «La literatura popularista al País Valenciàdurant la Decadència», Estudis de literatura catalana al País Valencià, Benidorm/Alicante, Ajuntament de Benidorm / Universitat d'Alacant, pp. 55-74.

Fuertes Zapata, Joan Vicent (2014) «La font de Llíria: Edició del primer milacre vicentí publicat (1822)», Scripta, núm. 4, pp. 96-110.

Fuertes Zapata, Joan Vicent \& Vilaplana, David (2014) «Els milacres vicentins del segle XIX: A propòsit d'un nou camp de recerca», eHumanista/IVTTRA, 5, pp. 190-196.

Martí Mestre, Joaquim (2017) Diccionari de fraseologia (segles XVII-XXI), València, Publicacions Universitat de València.

Martí-Badia, Adrià (2014) «La contribució de Vicent Boix i Ricarte (1813-1880) a la recuperació de la consciència lingüística dels valencians», eHumanista/IVITR A, 5, pp. 52-74.

Martínez Ortiz, José (1955) «Ensayo de un catálogo de milacres de San Vicente Ferrer», Revista Valenciana de Filología, IV, 239-264.

Narbona Vizcaíno, Rafael (2015) «El Centenar de la Ploma», Ciudad y Reino: claves del siglo de oro valenciano, València, Ajuntament de València, pp. 48-50

Pedraza, Pilar (1982) Barróco efímero en Valencia, València, Ajuntament de València.

Ribelles Comín, Josep (1978). Bibliografía de la lengua valenciana, Madrid, Ministerio de Educación y Ciencia, vol. 4.

Roca Ricart, Rafael (2013) «El record de sant Vicent Ferrer al llarg dels segles XIX i XX», Els valencians en el Compromís de Casp i en el Cisma d'Occident, València, Institució Alfons el Magnànim, pp. 503-526.

Sanchis Guarner, Manuel (1980) Els inicis del teatre valencià modern 1845-1874, València, Institut de Filologia Valenciana. 
Juan Vicente Fuertes Zapata. Els bandos de Valènsia o la paraula de sen Vicent Ferrer (1855): el primer milacre de Vicent Boix

Sansano, Gabriel (2014) «El teatre popular del segle XIX, dos exemples: Bernat i Baldoví i Eduard Escalante», Estudis filològics en homenatge al professor Joan J. Ponsoda, Alacant, Departament de Filologia Catalana de la Universitat d'Alacant, pp. 313-331

Serrano Morales (1898) Reseña bistórica en forma de diccionario de las imprentas que han existido en Valencia, València, Impremta de F. Doménech.

Sirera, Josep Lluís (1994), «Del sainet valencià i els seu límits», L’Aiguadolg, núm. 19-20, pp. 35-42. . (2008) «Misteris del Corpus de València», Estudios sobre teatro medieval, València, Publicacions de la Universitat de València, pp. 203-207. 